LETTERS TO THE EDITOR.

The United States, their Growth in Population in Two Hundred Years.

[T'he following letter was received from the Hon, W. E. Gladstone, in response to a copy of Science mailed him, containing Gen. M. C. Meigs's article on the above subject.]

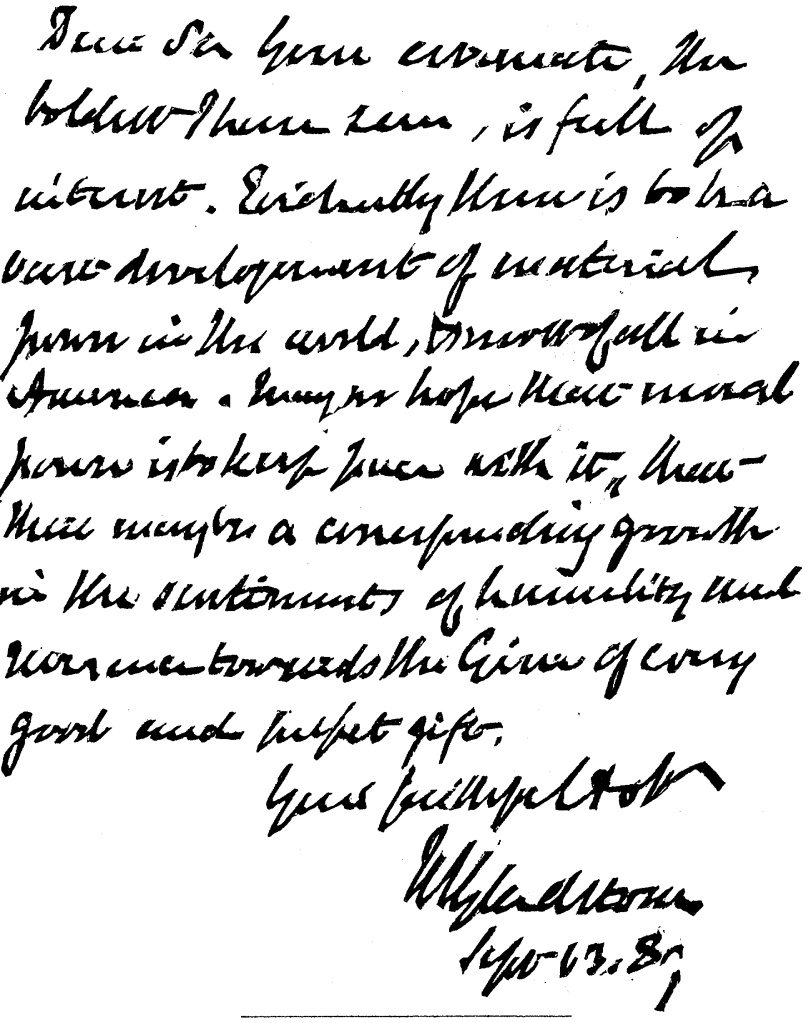

The Pennsylvania Weather Review.

THE monthly weather review of the Pennsylvania State Weather Service for August last contains an isothermal map of the State for the normals of the month, whose atrocious absurdity is paralleled only by the isothermal maps of New Hampshire in the report on the geology of that State several years ago. The isotherm of $67^{\circ}$ performs the extraordinary feat of branching three times in its traverse of Pennsylvania. Three other isotherms end abruptly within the limits of the State, apparently not knowing how to get out. The lobate isotherm of $7 \mathrm{I}^{\circ}$, that enters the State from the south and includes Gettysburg, fails to surround the adjacent isotherm of $74^{\circ}$, which reaches Harrisburg. It is remarkable that a travesty like this should appear under the direction of the committee on meteorology of the Franklin Institute of Philadelphia.

\section{Reformed Spelling.}

So far, all attempts to introduce a reformation in spelling seem to have failed. The changes that are recommended by the philological societies and approved by scholars are disregarded, Mr. Ellis's "Glossic" has been before the public nearly twenty years, Dr. Hill's efforts for six years at Waltham produced no permanent effect, it is doubtful if Mr. Bell's "World English" will fare better, and Hosea Bigelow spelling is dropped by every one after they have wearied themselves over a few lines.

While so much study has been given to the changes that are desirable, the best way to introduce them has perhaps been less considered. The eye is educated to catch syllables and words at a glance, and soon tires of picking out letters, although their combination may represent the sounds of words correctly. It is true that children can be easily taught to read phonetics; but, as one who has learned a foreign language lays it aside in his native land, so does the phonetic expert for the printed matter he finds in daily use, and the language floats on, unchanged and stationary.

How much, then, is it wise to attempt? Can any changes be proposed acceptable to readers, and such that printers will use them? Instead of attempting to introduce a phonetic system that is perfect, it may be well to employ one that is practical, and better than that at present in use, but not differing from it enough to embarrass the reader, and to keep words of uniform spelling if the correct sound of the letters in them is misused. No new letters should be used; nor does the eye tolerate new symbols, nor the use of accents, to determine sounds. This narrows the field in which changes can be made, yet leaves it large enough to furnish a spelling that will recommend itself to printers, foreigners, and illiterates; while children instinctively adopt it, when they can escape from the tyranny of the spelling-book, because it is uniform, and regulated by analogy.

First as regards the vowel-sounds. There seems to be no good reason to change the short sound of $a$. Its sound as in trade is fixed by $e$ mute in all words except four. Its sound as in marry is fixed by the double consonant. "Glossic" doubles $a$ in father, and adds $u$ in water. Short $e$ need not be changed. It is lengthened when it is in a final syllable or followed by $e$ mute, which Professor Marsh tells us requires four per cent of all printed matter. "Glossic" uses $e i$ for long $i$, which does not displease the eye. Of the four sounds of $o$, that as in tone is controlled by $e$ mute or by accent in pronunciation. The sound as in move occurs in twelve words, which may be memorized. Words with the sound as in dove might perhaps drop $e$ mute. The bête noire ou, with its seven sounds, has already caused a rebellion, as in plow for the time-honored plough, and may gradually drop most of them.

Of the consonants, $c$ is hard before $a, o, u$, which can easily be remembered, as it will be difficult to displace it by $k ; g$ has both hard and soft sounds before $e$ and $i$, where $j$ could be substituted, as jenuine. There would be few mourners at its burial should the printers condescend to drop $u$ after $q$. The change to tion for shun is displeasing, and its pronunciation is uniform. The printing $d t$ this for this is a stumbling-block in the way of any change.

The changes noted above are the principal ones that would go far to conform the spelling of the language to its pronunciation.

Perhaps the best way to have any changes adopted would be to have the most desirable printed on cards, to be kept in plain sight at every case of type, and have some editor who has the improvement of the language at heart print one article in his daily paper, with the approved spelling. If it is favorably received, increase it gradually as the readers approve it. The end can be gained by keeping the changes before the eye until they are accepted by habit.

W. C. Bryant used to say, "When you reformers agree among yourselves as to what you want, it will be time enough for us of the press to give the matter our attention." It cannot now be said that there is uncertainty as to the proposed reform. The action of the phonological societies, the efforts of linguists, the whole literature of phonetics, furnish a magazine to supply all that is needed to move upon the conservative forces that delay reform But the press should take the initiative: for with little effort they can make it familiar to every reader, and give it success. The results on the brotherhood of mankind will be such that every one who is in a position to forward the reform should take an active share in its introduction.

M.
INDUSTRIAL NOTES.

Electric Apparatus for South Africa.

OUR readers are well acquainted with the many electric-railway installations which have been made during the past two years, and with the fact that the manufacture of electric apparatus for this work has grown rapidly. It is now estimated that there are from I 50 to 200 electric street-railways in this country, either in operation or in course of construction.
Electricity promises to be the coming medium for transmission of power not only for street-railways, but also for mining industries; and it is hard to imagine an agent for transmitting power which is more easily handled, and the apparatus for which is, on the whole, more economical and inexpensive.

Among the electric mining plants which are now being installed by American manufacturers of electric apparatus, who lead the rest of the world, are a number not only in this country, but 